\title{
Identity Formation among Teenagers: The Role of Training Camp
}

\author{
Tayebeh Nikraftar \\ Assistant Prof, Faculty of Entrepreneurship, University of Tehran, Tehran, Iran \\ nikraftar@ut.ac.ir
}

Keywords: Jihadi training camp, Professional identity formation, Teenagers

\begin{abstract}
The aim of the present study was to examine the impact of jihadi camps on the identity formation of teenagers in Iran. Seventy-six campers participated in the study and were randomly divided into control $(n=42)$ and experimental groups $(n=34)$. The control group does not follow the camp's regular program while the experimental group attended to the camp's regular program. All participants completed the Dellas Identity Status Inventory (DISI) (Dellas and Jernigan, 1987); this questionnaire consists of two subscales of achiever: commitment and exploration. The results revealed statistically significant differences on the experimental and nonexperimental group, in two specific attitude subscales. These findings imply that participation in this particular camp can have a positive influence on teenagers' professional Identity.
\end{abstract}

\section{Introduction}

The main challenges of adolescence from the perspective of developmental psychologists are to achieve identity. The aim of this research is to research on adolescents' professional identity.

Identity formation is a process involving many knowledge sources, such as knowledge of affect, human relations, and subject matter [1]. Gee et al. [7] suggests that as people acquire discourses they form the social self in new ways. Given the complex interweaving of values, social forms, linguistic forms, beliefs, and roles which comprise a discourse in which people feel at home [10] and without giving it much critical reflection people acquire values, world views, and perceptions of others. These perceptions are acquired within the same contexts as peoples' sense of what is right, what is wrong, and how the social world is modeled. In that way, people construct their social selves within the everyday realities that they inhabit [10]

Professional Identity formation leads to the growth of ego. In fact, to have the professional identity (a clear picture of the goals and personal abilities) help to find the appropriate job in future [17].

In the jihadi camps special programs have been designed with young people in areas far from their residences. In these camps youth group to experience a social life and they do all the things together and their teacher sonly play the role of facilitator. Teens can participate go and help to many poor areas. Their activities are mostly construction ones. The Jihadi camps, hold a series of spontaneous activity by students, volunteers and other young people in deprived areas. These camps according to their capacities and capabilities offer a variety of services including civil engineering projects, agricultural services, medical treatment, education and training as well as cultural activities.

Accordingly, the Jihadi camps provide learning and training needs during participation and to professional identity. In this direction, researchers of this study sought to answer the main question: "is jihadi camps affected professional identity of teens "?

\section{Literature Review}

In earlier literature, the concept of identity was often vaguely described in terms of the self and one's self-concept from this perspective, identity of the self is seen to be established and maintained either through negotiations within social situations, or through social roles that are internalized by the individuals. Identity can generally be defined as who or what someone is, the various meanings people can attach to themselves, or the meanings attributed by others Nowadays, identity formation is conceived as an ongoing process that involves the interpretation and 
reinterpretation of experiences as one lives through them. The process of professional identity formation explores students' transitions from higher education out into working life. More specifically, it is based on graduates' professional trajectories from one community to another [12] and how they become professional individuals. When entering higher education and joining an educational program, students not only become aware of a specific body of knowledge and skills, they are also exposed to different communities of practice, with particular sets of traditions, activities and boundaries development of a professional identity is not just dependent on the learning community, but also formed through a negotiation between the individual and a specific context, such as an educational program [19]. According to Reid et al. (2007), these communities affect how the graduates become prepared for and identify with their future work.

Identity was first posed by Erikson in 1950, as a genuine issue. Erikson's theory was tested and elaborated by James Marcia. Through semi- structured, open - ended interviews he came to the conclusion that there are four identity statuses long the identity continuum suggested by Erikson: 1) identity achievement 2 ) identity moratorium 3 ) identity foreclosure 4) identity diffusion.

Erikson also believed that social experience and interaction with the world is key to development of a self-concept, a phenomenon he described as ego identity [6]. Professional identity formed through progressively complicated stages (life stage, career stage and service learning experiences). Learning how to integrate emotions and intellect can be one of the most challenging tasks of young adulthood and beyond. Individual integration is based upon years of skill building and life experience. It involves identifying and expressing emotion based on intellect, rather than reaction, while concurrently navigating personal behavior within a structured society [9].

The formation of identity is a key component or developmental challenge according to Erikson. The process of identity development requires individuals to define themselves in relation to the world around them.

According Berger and Luckmann [2] Identity is a phenomenon that emerges from the dialectic between individual and society. Identity types, on the other hand, are social products tout court, relatively stable elements of objective social reality (the degree of stability being, of course, socially determined in its turn).

The interpersonal aspects of the professional identity development process involve the professional community and its role in shaping the new professional. O'Byrne and Rosenberg (1998) proposed a sociological perspective on identity development, in which the professional acculturation process emerges through guided participation with the professional community. In this context, new professionals are socialized in the language of therapy; learn what is expected and what they can expect; and learn to behave as "native speakers" in the new culture through observation, supervision, consultation, and practice. Dollarhide and Miller [5] summarized this process as immersion in a professional culture through which one learns professionally appropriate attitudes, values, modes of thinking, and strategies for problem solving. Social identity is not given but constructed as individuals engage with social contexts and in social interaction [7]. Nicholson [11] argued that, depending on the job conditions, four outcomes can occur as employee's transition into new work roles: absorption, determination, exploration, and replication. These outcomes mark a change in person (absorption), role (determination), both (exploration), or neither (replication).

James Marcia [13] hypothesized that identity development involves two steps. First, the adolescent must break away from childhood beliefs to explore alternatives for identity in a particular area. Second, the adolescent makes a commitment as to their individual identity in that area.

Based on Erikson's ideas, two criteria for the presence of identity formation were proposed: exploration and commitment. Exploration referred to some period of re-thinking, sorting through, and trying out various roles and life plans. The exploratory period is a time when the late adolescent is actively involved in choosing among meaningful alternatives. Commitment referred to the degree of personal investment the individual expressed in a course of action or belief.

Present Study used these two criteria (commitment and exploration) to assess adolescent identity. 


\section{Methodology}

Participants: This is Semi-experimental research. In this method, the researcher to control some of the factors examined. In this study, adolescents who participate in Jihadi training camp were considered experimental group (sample 2) and young people who did not participate in Jihadi camps (sample 1), were used as a control group. Accordingly, identity status variables were measured to determine a significant difference or no difference between the two groups. Participants were seventy-six teenagers, from the east area of Tehran. The campers were divided into two groups, an experimental group $(n=42$ men, $M=15.03$ years old $)$ that participated in camp program, and a control group ( $\mathrm{n}=34$ men, $\mathrm{M}=15.43$ years old $)$.

Instrument: Dellas Identity Status Inventory developed by Dellas and Jernigan [4]. It contains 35 items and allow people ascription one of the following types of identity status, that is, towards achiever, moratorium, foreclosure, diffusion-diffusion, and diffusion-luck. This division is similar to the one developed by James Marcia (1966). For this situation we followed (DISI) of separating achiever into two group questions, one measures commitment and other ones exploration. The Cronbach Alpha coefficients of the two sub-scales are reported as 0.80 and 0.81 respectively. Responses were given on a 5-point Likert scale from 1 (disagree) to 4 (agree). Higher scores indicate more positive attitudes. T-student and Leven's test were used for data analysis.

Procedures: In an initial phase of our methodological plan and in order to answer our research question, "what differences are in identity status according to the camps attended by the students?" We used Dellas Identity Status Inventory developed by Dellas and Jernigan [4] to understand how participants in camp plan were being more achiever than individuals who did not participate in Jihadi camp program. The data collected during summer 2015, in disadvantaged areas of southern Iran.

\section{Data Analysis}

Statistical analysis employed SPSS 16 for windows. Concretely it was conducted an ANOVA in order to verify if there were significant differences in the mean scores on the questionnaire dimensions according to the camp attended. Leven's Test was conducted. It is an inferential statistic used to assess the equality of variances for a variable calculated for two or more groups. Some common statistical procedures assume that variances of the populations from which different samples are drawn are equal. Levene's test assesses this assumption. It tests the null hypothesis that the population variances are equal (called homogeneity of variance or homoscedasticity). If the resulting P-value of Levene's test is less than some significance level (typically 0.05), the obtained differences in sample variances are unlikely to have occurred based on random sampling from a population with equal variances.

\section{Results}

Significant main effects of sample emerged in all ANOVAs that were conducted. With respect to the continuous identity style measures, there was a significant main effect of sample on the Commitment, $F=1.7, p<.05$; Exploration, $F=1.8, p<.05$. The mean Commitment score was greater in Sample $2(M=3.17, S D=1.6)$ than in Sample $1(M=2.8, S D=1.03)$. The mean Exploration score was greater in Sample 2( $M=3.1, S D=1.9)$ than in Sample $1(M=2.9, S D=1.4)$

Participants reported positive attitudes towards participating in Jihadi camp. Analysis of variance revealed significant main effects regarding participating in camp. Whereas responses of the control group had lower means in two sub scale. Particularly, commitment of experimental group was changed significantly (Table1). 
Table 1. Results of Data Analysis.

\begin{tabular}{|c|c|c|c|c|c|c|}
\hline \multirow{2}{*}{$\begin{array}{c}\text { Variable } \\
\text { (Assumption of the } \\
\text { equality of variance } \\
\text { between the two groups) }\end{array}$} & \multicolumn{2}{|c|}{ T Student test } & \multicolumn{2}{c|}{ Leven's Test } & \multicolumn{2}{|c|}{ Means } \\
\cline { 2 - 7 } & $\mathrm{t}$ & Significant & $\mathrm{F}$ & $\mathrm{P}$ & $\begin{array}{c}\text { Control } \\
\text { Group } \\
\text { (sample1) }\end{array}$ & $\begin{array}{c}\text { Non control } \\
\text { Group } \\
\text { (sample 2) }\end{array}$ \\
\hline commitment & 3.48 & 0.016 & 1.7 & 0.000 & 2.8 & 3.17 \\
\hline exploration & 3.5 & 0.00 & 1.8 & 0.000 & 2.9 & 3.1 \\
\hline
\end{tabular}

Table 2. Group statistics for exploration variable.

\begin{tabular}{|c|c|c|c|}
\hline & Frequency & Mean & Standard deviation \\
\hline Control Group (sample 1) & 34 & 2.8 & 0.62 \\
\hline Non control Group (sample 2) & 42 & 3.1 & 0.44 \\
\hline
\end{tabular}

Table 3. Group statistics for commitment variable.

\begin{tabular}{|c|c|c|c|}
\hline & Frequency & Mean & Standard deviation \\
\hline Control Group (sample 1) & 34 & 2.5 & 0.61 \\
\hline Non control Group (sample 2) & 42 & 3.3 & 0.51 \\
\hline
\end{tabular}

\section{Discussion}

Despite increasing interest in identity, and the importance of it of teenagers there is little research on how individuals construct professional identities. The goal of the current research was to find the impacts of camps on students' identity in Iran.

The hypothesis of the present study was that the Jihadi camp would have a positive effect on the identity formation of teenagers. Results of the analysis supported our hypothesis on the positive effect of the camp on two subscales. In general, in terms of status means the results seem similar to previous work $[3,15]$. The achiever identity status is characterized by exploration and commitment. Current study emphasizes that the Jihadi camp is a symbol of a discourse, the discourse of resistance and efforts to carry different duties. Jihadi camps create special social realm until people with hardworking to find their identity.

According to [6], Identity is a phenomenon that emerges from the dialectic between individual and society. Gendron [8] suggested, experiential learning opportunities reinforces career choice, provided opportunities for applied learning, opened doors to job opportunities and provided effective role models for students. Our research contributes to our understanding of identity construction by describing the importance of the relationship between "doing" and "being" among teenagers.

It would appear beneficial for students to be presented with opportunities to engage in a diverse array of activities, so that there is an increased likelihood that they will discover some things that surprise them with the feeling "Where has this been all my life ... why didn't I know about this before?". The effectiveness of camp activities derives from the increased likelihood that educational experiences will be accompanied by the various markers for intrinsic motivation. What better way to find someone to be?

\section{Conclusion}

Our work extends and bridges various studies that comprise the literature on identity work. To our knowledge, although others have begun to outline the factors important to identity work, we are the first to show how this process occurs through camps in schools. More generally, we turn 
scholars' attention toward the motivation for identity customization. In doing so, we take lessons from research on "meaningful work," according to which work is meaningful to an individual to the extent that it reflects who the individual is and as Kahn (1990) noted, work becomes meaningful when one's "preferred self" can be expressed through one's work and through one's membership in an organization. Building on this research, we argue that achieving alignment between identity and work is a fundamental motivator in identity construction.

However, future research using different individuals (e.g. Girls students) as the sample might consider using different outcome variables. The outcome variables should accurately evaluate and measure identity formation based upon the characteristics of the specific individuals.

\section{References}

[1] D. Beijaard, P.C. Meijer, N. Verloop, Reconsidering research on teachers' professional identity, Teaching and Teacher Education. 20 (2004) 107-128.

[2] P.L. Berger, T. Luckmann, The social construction of reality: a treatise in the sociology of knowledge, Vol. 589, Anchor Books, 1966.

[3] M. Dellas, L.P. Jernigan, Development of an objective instrument to measure identity status in terms of occupation crisis and commitment, Educational \& Psychological Measurement. 41 (1981) 1039-1050.

[4] M. Dellas, L.P. Jernigan, Occupational identity status development, gender comparisons, and internal-external locus of control in first-year Air Force cadets, Journal of Youth and Adolescence. 16 (1987) 587-600.

[5] C.T. Dollarhide, G.M. Miller, Supervision for preparation and practice of school counselors: Pathways to excellence, Counselor Education and Supervision. 45 (2006) 242-252.

[6] E.H. Erikson, Childhood and society, W.W. Norton and Co, New York, 1950.

[7] J.P. Gee, G. Hull, C. Lanshear, The new work order: behind the language of the new capitalism, Allen and Unwin, St. Leonards, 1996.

[8] T. Gendron, The Professional identity development of gerontologist: An experiential learning approach, Virginia Commonwealth University, Richmond, 2011.

[9] G. Labouvie-Vief, Cognitive-emotional integration in adulthood, in: K.W. Shaie, M.P. Lawton, Annual Review of Gerontology and Geriatrics, Springer Publishing, New York, 1997, pp. 206-237.

[10] D. Lundell, T.G. Collins, Towards a theory developmental education: the centrality of discourse, in: D. Lundell, J.L. Higbee (Eds.), Theoretical perspectives in developmental education, Minneapolis: Centre for Research on Developmental Education and Urban Literacy, General College, University of Minnesota, 2001, pp. 3-20.

[11] N.A. Nicholson, Theory of work role transitions, Administrative Science Quarterly. 29 (1984) $172-191$.

[12] S. Nyström, Graduates doing gender as early career professional, Career development international. 15(4) (2010) 324-337.

[13] J. Marcia, Identity and self-development, in: Richard Lerner, Anne Peterson, and Jeanne Brooks-Gunn eds., Encyclopedia of Adolescence, Garland, New York, 1991.

[14] J.E. Marcia, Development and validation of ego identity status, Journal of Personality and Social Psychology. 3 (1966) 551-558.

[15] D. Martins, C. Carvalho, Teacher's feedback and student's identity: an example of elementary school students in Portugal, Procedia-Social and Behavioral Sciences. 82 (2013) 302-306. 
[16] K. O'Byrne, J.I. Rosenberg, The practice of supervision: A sociocultural perspective, Counselor Education and Supervision. 38 (1998) 34-42.

[17] D. Operariro, S.T. Fiske, Integrating social identity and social cognition: A framework for bridging diverse perspectives, in: D. Abrams, M.A. Hogg, Social Identity and Social Cognition, Blackwell, Oxford, 1999.

[18] A. Reid et al., Identity and engagement for professional formation, Studies in Higher Education. 33(6) (2008) 729-742.

[19] E. Wenger, Communities of practice: learning, meaning and identity, Cambridge University Press, Cambridge, 1998. 